OPEN ACCESS

Edited by:

Deborah K. Dunn-Walters,

University of Surrey,

United Kingdom

Reviewed by:

David Nemazee,

Scripps Research Institute,

United States

Paolo Casali,

The University of Texas Health

Science Center San Antonio,

United States

*Correspondence:

Thereza Imanishi-Kari

thereza.imanishi-kari@tufts.edu

Specialty section:

This article was submitted

to B Cell Biology,

a section of the journal

Frontiers in Immunology

Received: 26 May 2017

Accepted: 22 August 2017

Published: 13 September 2017

Citation:

McDonald G, Medina CO,

Pilichowska M, Kearney JF, Shinkura R, Selsing E, Wortis HH, Honjo $T$ and Imanishi-Kari T (2017)

Accelerated Systemic Autoimmunity

in the Absence of Somatic Hypermutation in 564lgi: A Mouse

Model of Systemic Lupus with

Knocked-In Heavy and

Light Chain Genes.

Front. Immunol. 8:1094.

doi: 10.3389/fimmu.2017.01094

\section{Accelerated Systemic Autoimmunity in the Absence of Somatic Hypermutation in 564lgi: A Mouse Model of Systemic Lupus with Knocked-In Heavy and Light Chain Genes}

\author{
Gabrielle McDonald', Carlos O. Medina', Monika Pilichowska², John F. Kearney ${ }^{3}$, Reiko \\ Shinkura ${ }^{4}$, Erik Selsing ${ }^{1}$, Henry H. Wortis ${ }^{1}$, Tasuku Honjo ${ }^{5}$ and Thereza Imanishi-Kari ${ }^{1 *}$ \\ ${ }^{1}$ Department of Integrative Physiology and Pathobiology, Sackler School of Graduate Biomedical Sciences, Tufts University \\ School of Medicine, Boston, MA, United States, ${ }^{2}$ Department of Pathology and Laboratory Medicine, Tufts Medical Center, \\ Boston, MA, United States, ${ }^{3}$ Department of Microbiology, University of Alabama, Birmingham, AL, United States, \\ ${ }^{4}$ Department of Immunology, Nagahama Institute of Bioscience and Technology, Nagahama, Japan, ${ }^{5}$ Department of \\ Immunology and Genomic Medicine, Graduate School of Medicine, Kyoto University, Kyoto, Japan
}

564lgi mice have knocked-in immunoglobulin $(\mathrm{lg})$ heavy $(H)$ and light $(L)$ chain genes that encode an autoantibody recognizing RNA. Previously, we showed that these mice produce pathogenic IgG autoantibodies when activation-induced deaminase (AID) is expressed in pre-B and immature B cells but not when it is expressed only in mature $B$ cells. AID has two functions; it is necessary for somatic hypermutation (SHM) and class switch recombination (CSR). To determine the role of each of these functions in the generation of pathogenic autoantibodies, we generated 564lgi mice that carry a mutant AID-encoding gene, Aicda (AicdaG23S), which is capable of promoting CSR but not SHM. We found that 564lgi Aicda ${ }^{\mathrm{G} 23 \mathrm{~S}}$ mice secreted class-switched antibodies (Abs) at levels approximately equal to 564lgi mice. However, compared to 564lgi mice, 564lgi Aicda ${ }^{\text {G23s }}$ mice had increased pathogenic IgG Abs and severe systemic lupus erythematosus-like disease, including, glomerulonephritis, and early death. We suggest that in 564lgi mice SHM by AID changes Ig receptors away from self reactivity, thereby mitigating the production of autoantibody, providing a novel mechanism of tolerance.

\footnotetext{
Keywords: activation-induced cytidine deaminase, somatic hypermutation, class switch recombination, systemic lupus erythematosus, autoantibodies, pathogenic antibodies, B cell central tolerance, RNA-specific antibodies
}

\section{INTRODUCTION}

Various systemic autoimmune diseases exhibit a high frequency of antibodies (Abs) that recognize nucleic acid antigens, suggesting that nucleic acids may have properties that promote the breaking of B-cell tolerance. Autoantibodies that bind DNA are more commonly studied, but RNA-binding Abs are frequent in systemic lupus erythematosus (SLE) patients and, unlike anti-DNA, correlate with disease severity (1). In order to understand the mechanisms involved in the production of 
pathogenic autoantibodies, we produced the 564Igi mouse model of SLE; this strain has knocked-in immunoglobulin (Ig) heavy $(\mathrm{H})$ and light $(\mathrm{L})$ chain genes that encode an autoantibody that recognizes RNA. 564Igi mice have only low-levels of serum antiRNA IgM Abs, consistent with the fact that their splenic B cells are anergic and apparently tolerized (2). Unexpectedly, however, IgG2a/IgG2b anti-RNA Abs are found at high levels in the sera of 564Igi mice and IgG Abs that exhibit the 564 idiotypic marker $\left(\mathrm{Id}^{+}\right)$are found in the glomeruli, resulting in an SLE-like disease (2). The production of these anti-RNA Abs is toll-like receptor 7 (TLR7) and TLR8 dependent $(2,3)$. As these anti-RNA IgG Abs are pathogenic, they resemble those found in SLE patients having RNA-specific Abs, indicating that the 564Igi mouse is an excellent model for unraveling the developmental mechanisms that give rise to autoantibodies that recognize nucleic acids, thereby providing insight into potential new targets for intervention in disease progression.

The fact that B cell tolerance is breached in 564Igi mice (2) despite the absence of detectable, non-anergic $\operatorname{IgM}^{+} \mathrm{Id}^{+} \mathrm{B}$ cells in the periphery, led to the search for the cells responsible for the production of pathogenic $\mathrm{Id}^{+} \mathrm{Abs}$ in these mice. If anergic mature $B$ cells in vivo are unable to differentiate into antibody-producing cells, then some $\mathrm{Id}^{+} \mathrm{B}$ cells must be able to evade anergy to produce the pathogenic $\mathrm{Id}^{+}$Abs. Thus, there must be a breach in central and/or peripheral tolerance.

The bone marrow (BM) is the site where autoreactive, surface $\mathrm{IgM}^{+}$adult origin $\mathrm{B}$ cells first encounter and respond to self-antigen by upregulating expression of the recombination-activating gene (RAG) and initiating receptor editing (4-8). Activationinduced cytidine deaminase (Aicda/AID), which is required for somatic hypermutation (SHM) and class switch recombination (CSR) of Ig genes, is highly expressed in mature germinal center (GC) B cells, where it enables the generation of high affinity Abs to environmental antigens (9). Our lab and others (10-16) have discovered that, in mice and humans, expression of activationinduced deaminase (AID) can be induced in developing B cells resulting in both CSR and SHM. These findings are provocative because they suggest possible roles for AID in B cell tolerance and B cell-dependent autoimmunity.

The production of IgG autoantibodies in humans is crucial for the pathogenesis of SLE (17-20). We previously found that AID is necessary for the production of pathogenic antibody in 564Igi mice $(3,21)$. Surprisingly, AID activity in mature B cells is not sufficient for the production of autoreactive IgG (21). We found that Aicda expression and CSR in developing B cells are critical for the production of pathogenic IgG autoantibodies in these mice $(3,21)$. Of note, Aicda expression is elevated in pre-B and immature BM B cells from 564Igi mice (21).

A likely explanation for the requirement for AID activity in developing B cells to produce autoantibodies in 564Igi stems from examination of mechanisms of central B cell tolerance. During B cell development, before B cell maturity, strong cross-linking of IgM BCR can signal the induction of tolerance by deletion, anergy, or receptor editing mechanisms $(22,23)$. In contrast, IgG BCR cross-linking induces signaling events that lead to B-cell activation, proliferation, and differentiation $(24,25)$. Because the signal pathways downstream of surface IgM and IgG differ,
CSR can alter the post-activation fate of a B cell. We suggest that this change in signaling means that CSR from IgM to IgG in developing B cells allows self-reactive B cells to evade tolerance mechanisms.

It has been shown that self-reactive mature B cells in vitro can be activated through dual BCR and endosomal TLR signaling $(26,27)$ and that dual ligation of these receptors can induce AID expression and CSR (28). It has also been shown that immature $B$ cells in the BM can be activated by similar mechanisms $(21,29)$. Self-nucleic acid, which is abundant in the BM microenvironment (30), would have the potential to bind and stimulate the self-reactive BCRs found on the surface of many immature B cells (31). Once recognized, this self-antigen could be endocytosed and delivered to the endosome (32). In the endosome, TLR7 and TLR8, which recognize RNA, could potentially be stimulated by this internalized self-antigen (32), leading to the expression of Aicda, followed by premature CSR and the production of pathogenic IgG autoantibodies.

While AID-mediated CSR can facilitate the breaching of tolerance, several reports demonstrate that the absence of AID increases the production of self-reactive Abs, suggesting that AID also contributes to B cell tolerance $(33,34)$. One potential mechanism by which AID can mediate tolerance is through SHM of self-reactive Ig genes.

However, since a deficiency of AID results in the production of only IgM Abs, the role of AID in the prevention of pathogenic IgG antibody production remains unknown. In order to test this hypothesis, we developed a novel mouse 564Igi model with a knock-in mutation (G23S) in the Aicda gene (designated 564Igi $A i c d a^{G 23 S}$ ). This mutation leads to deficient SHM activity but has no apparent effect on CSR (35) and, thereby, separates the two AID functions. We used this mouse model to definitively determine the specific roles of SHM in central B cell tolerance.

\section{RESULTS}

\section{4lgi Aicda ${ }^{\mathrm{G} 23 s}$ and 564lgi Mice Have Equivalent Numbers of Spleen and BM B Cells}

In order to verify that a lack of SHM does not affect B cell development, we stained whole spleen and BM cell suspensions for B cells at various developmental stages. Here, we show that the introduction of anti-RNA antibody-coding Ig genes caused a decrease in both BM and splenic B cells in 564Igi mice (Figures 1A-D), confirming previously published results (21). Because 564Igi mice express the self-reactive 564 receptor, many B cells may be clonally deleted, accounting for the reduction in splenic and BM B cells. Similarly, 564Igi Aicda ${ }^{\mathrm{G} 23 \mathrm{~S}}$ mice had significantly fewer BM and splenic B cells than Aicda ${ }^{\mathrm{G} 23 \mathrm{~S}}$ controls (Figures 1A-D), likely due to the increase in clonal deletion caused by the presence of the 564 knock-in. However, there is no difference in the number of splenic or BM B cells found in 564Igi and 564Igi Aicda ${ }^{\mathrm{G} 23 \mathrm{~S}}$ mice (Figures 1A-D). Therefore, the lack of SHM does not affect B cell development in 564Igi mice. 


\section{A \\ Absolute number of $\mathrm{B220}^{+} \mathrm{B}$ cells in the bone marrow}

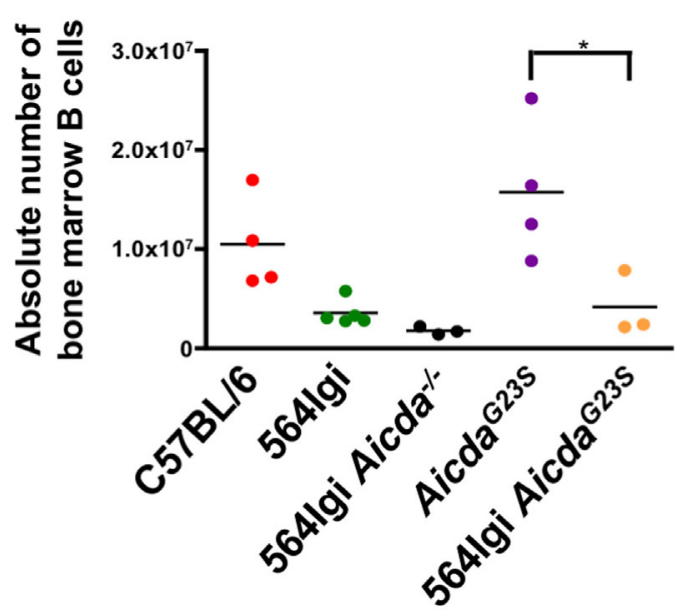

C
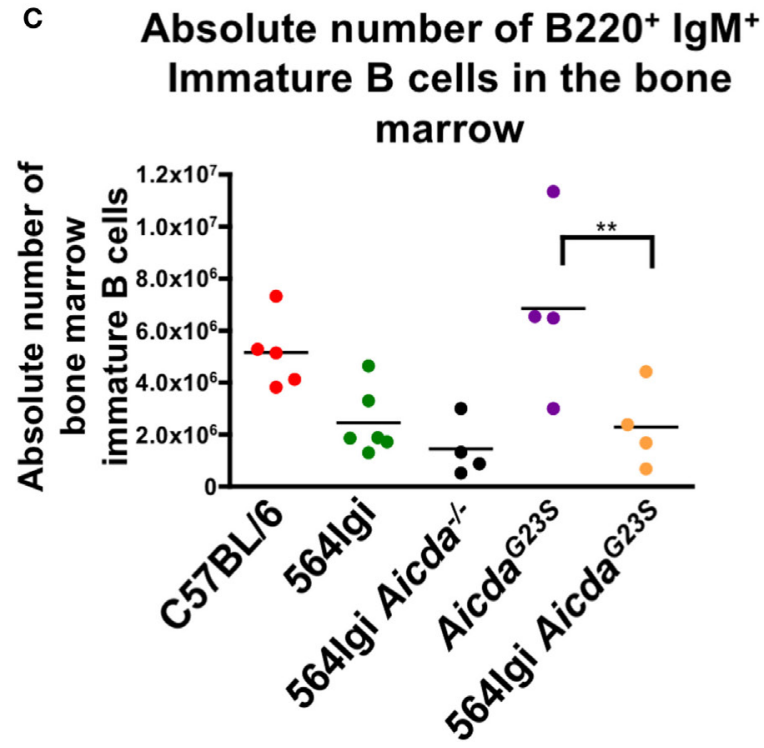

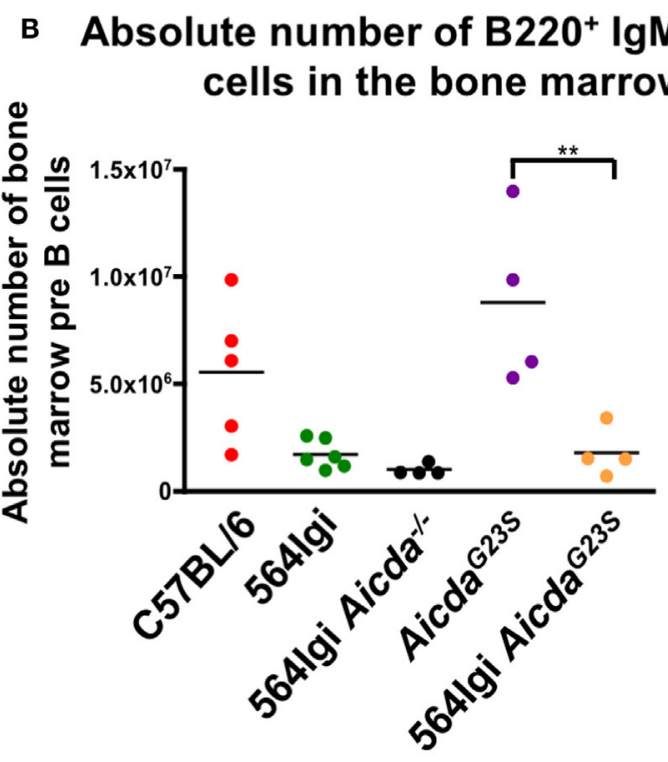

D

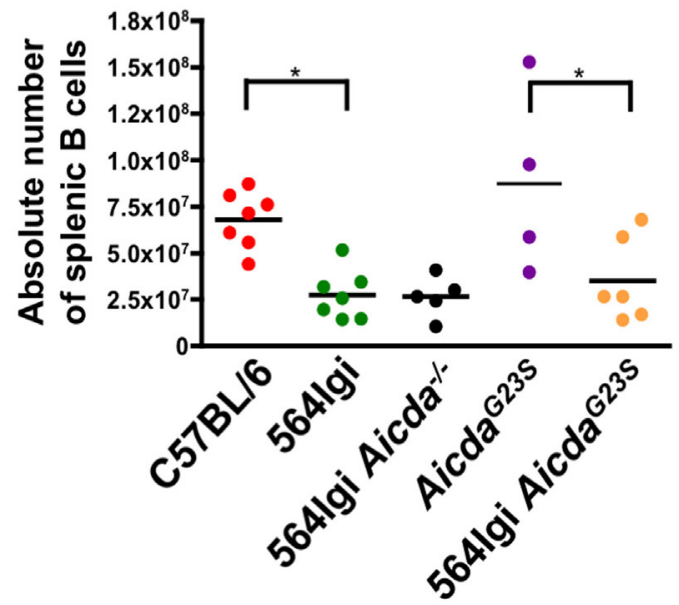

FIGURE 1 | 564lgi Aicda ${ }^{623 S}$ and 564lgi mice have equal numbers of splenic and bone marrow (BM) B cells. Total BM (A-C) or spleen (D) cell suspensions from the indicated mice were stained with fluorescent antibodies and analyzed by flow cytometry to detect B220+ B cell (A,D) B220+ lgM- pre B cells (B) and B220+ lgM+ immature B cells $(\mathbf{C})$. Shown is the absolute number of live cells in each animal with the mean shown as a horizontal line. Each point represents an individual animal.

\section{Elevated Levels of Aicda Are Found in the B Cells of 564lgi and 564lgi Aicda ${ }^{\mathrm{G} 23 \mathrm{~S}}$ Mice}

In order to verify expression levels of Aicda in the Aicda ${ }^{G 23 S}$ and 564Igi Aicda ${ }^{\mathrm{G} 23 \mathrm{~S}}$ mice, we performed RT-qPCR on sorted BM and splenic B cells using AID-deficient 564Igi mice as a negative control (564Igi Aicda ${ }^{-/-}$). Aicda ${ }^{G 23 S}$ mice expressed Aicda at levels comparable to C57BL/6 mice in both the spleen and BM, indicating that the G23S mutation in Aicda alone does not affect gene expression (Figure 2A). Splenic and BM B cells in 564Igi mice had elevated Aicda expression compared to C57BL/6 mice (Figure 2A). Similarly, 564Igi Aicda $a^{\mathrm{G} 23 \mathrm{~S}}$ mice had significantly elevated Aicda levels compared to Aicda ${ }^{G 23 S}$ mice in both the spleen and BM (Figure 2A). There was no significant difference in Aicda expression between 564Igi and 564Igi Aicda ${ }^{\mathrm{G} 23 \mathrm{~S}} \mathrm{~B}$ cells in the spleen. However, in the BM, 564Igi Aicda ${ }^{\mathrm{G} 23 \mathrm{~S}}$ mice had significantly more Aicda than 564Igi mice (Figure 2A).

\section{4lgi Aicda ${ }^{\mathrm{G} 23 \mathrm{~S}}$ Mice Have Normal IgG Antibody Titers}

$A i c d a^{G 23 S}$ and 564Igi Aicda ${ }^{\mathrm{G} 23 \mathrm{~S}}$ mice had circulating class-switched Abs at levels equal to $\mathrm{C} 57 \mathrm{BL} / 6$ and 564Igi mice, respectively (Figure 2B; Figure S1A in Supplementary Material). 564Igi $\mathrm{Aicda}^{-/-}$mice lack all IgG isotypes (36) and were used as a negative control. 564Igi $\mathrm{Rag}^{-/-}$mice lack T cells, and therefore, lack 
A Aicda expression in splenic B cells Aicda expression in bone marrow B cells
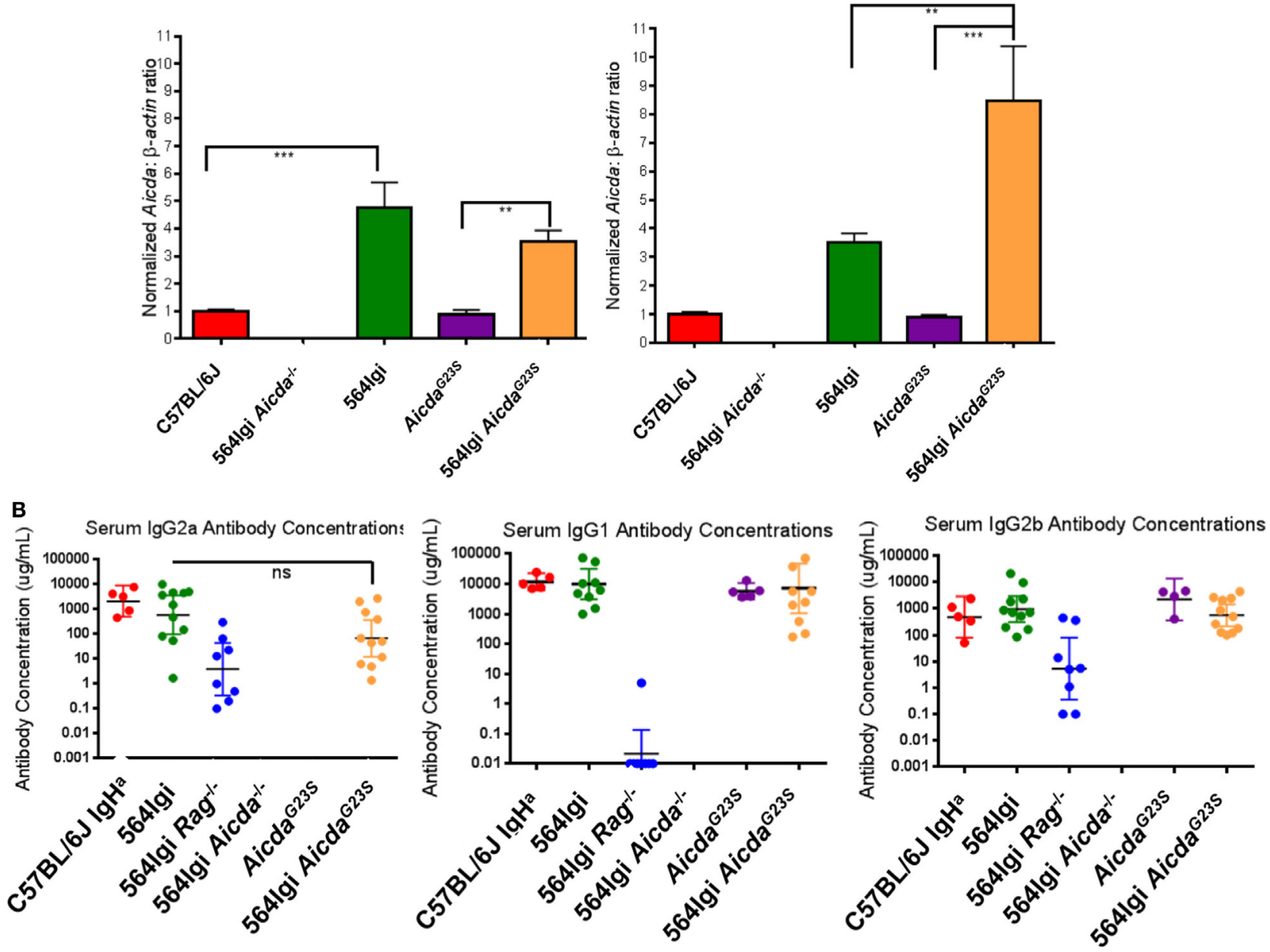

FIGURE 2 | B cells from 564lgi Aicda ${ }^{\mathrm{G} 23 S}$ mice expressed more Aicda and similar levels of IgG antibodies than 564lgi mice. (A) Quantitative real-time PCR analysis of Aicda expression in B220+ cell sort purified B cells from the spleen and bone marrow. Shown is the mean \pm SEM fold increase in Aicda expression over C57BL/6 from three independent experiments with three mice per experiment. (B) The concentrations of the indicated isotypes were measured by ELISA using a purified antibody of the indicated isotype as a standard. The horizontal line represents the geometric mean antibody concentration $\pm 95 \%$ confidence intervals for each mouse group. Each data point represents an individual mouse.

IgG1 isotype, that require T cell help (2), and thus were used as an additional control. It should be noted that C57BL/6 mice express the IgG2c allele and, therefore, secrete IgG2c Abs instead of IgG2a Abs. Because Aicda ${ }^{G 23 S}$ mice are on the C57BL/6 background, they also express the IgG2c allele and secrete IgG2c Abs at comparable levels to C57BL/6 mice (Figure S1B in Supplementary Material). 564Igi mice, on the other hand, were generated by introducing the 564 Ig genes into embryonic stem cells derived from 129 mice, which express the IgG2a allele. Mice were then bred back onto the C57BL/ 6 background for more than 20 generations, selecting for the 129-derived Ig locus containing the 564 knock-in genes (2). Therefore, any mice expressing the 564Ig genes will secrete IgG2a Abs.

For the IgG2a antibody titers C57BL/6 $\operatorname{IgH}^{\mathrm{a}}$ mice, which also express the IgG2a allele, were used as a control. There may be a slight decrease in serum IgG2a antibody concentrations in 564Igi Aicda ${ }^{\mathrm{G} 23 \mathrm{~S}}$ mice compared to 564Igi mice, although this is not statistically significant (Figure 2B). Ex vivo, there is also a slight decrease in IgG2a CSR in 564Igi Aicda ${ }^{\mathrm{G} 235} \mathrm{~B}$ cells that results in a significant decrease in IgG2a antibody secretion ex vivo (Figures S2A-C in Supplementary Material). While this may indicate that 564Igi Aicda ${ }^{\mathrm{G} 23 \mathrm{~S}} \mathrm{~B}$ cells switch to IgG2a less efficiently than 564Igi mice, there is no difference in CSR to IgG2b or IgG1 (Figure 2B; Figures S3 and S4 in Supplementary Material). Therefore, despite increased Aicda expression in 564Igi Aicd $a^{\mathrm{G} 23 \mathrm{~S}}$ mice (Figure 2A), there is no concomitant increase in general CSR activity, consistent with reports of negative regulation of Aicda both at the posttranscriptional and posttranslational levels (37-41).

\section{4lgi Aicda ${ }^{\mathrm{G} 23 \mathrm{~S}}$ Mice Have an Altered Distribution of Anti-RNA IgG Isotypes}

In 564Igi mice, SLE-like features have been shown to be largely mediated by IgG2a and IgG2b anti-RNA Abs that produce a characteristic nucleolar staining pattern when used for 
A

C57BL/6

564lgi 564lgi Aicda ${ }^{G 23 S}$
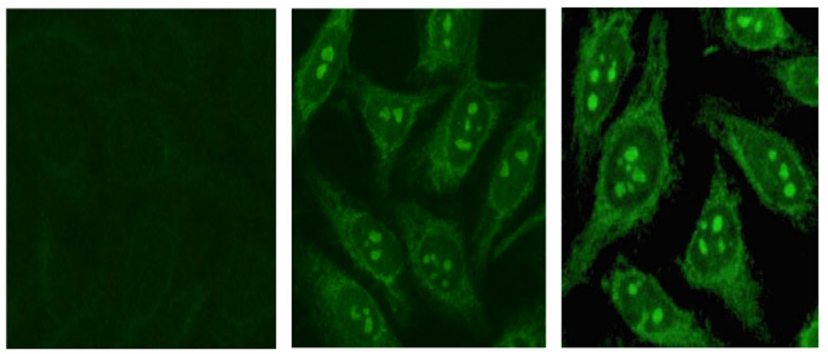

B

$\lg M$ anti-RNA

C

IgG2a antl-RNA
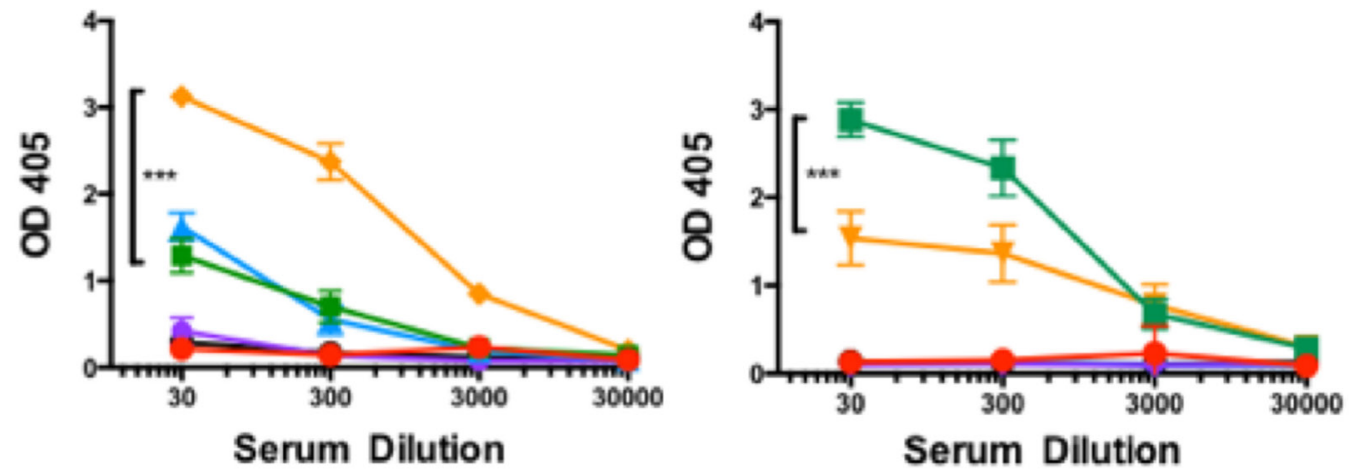

D

Ig G2b anti-RNA

E

IgG1 Anti-RNA
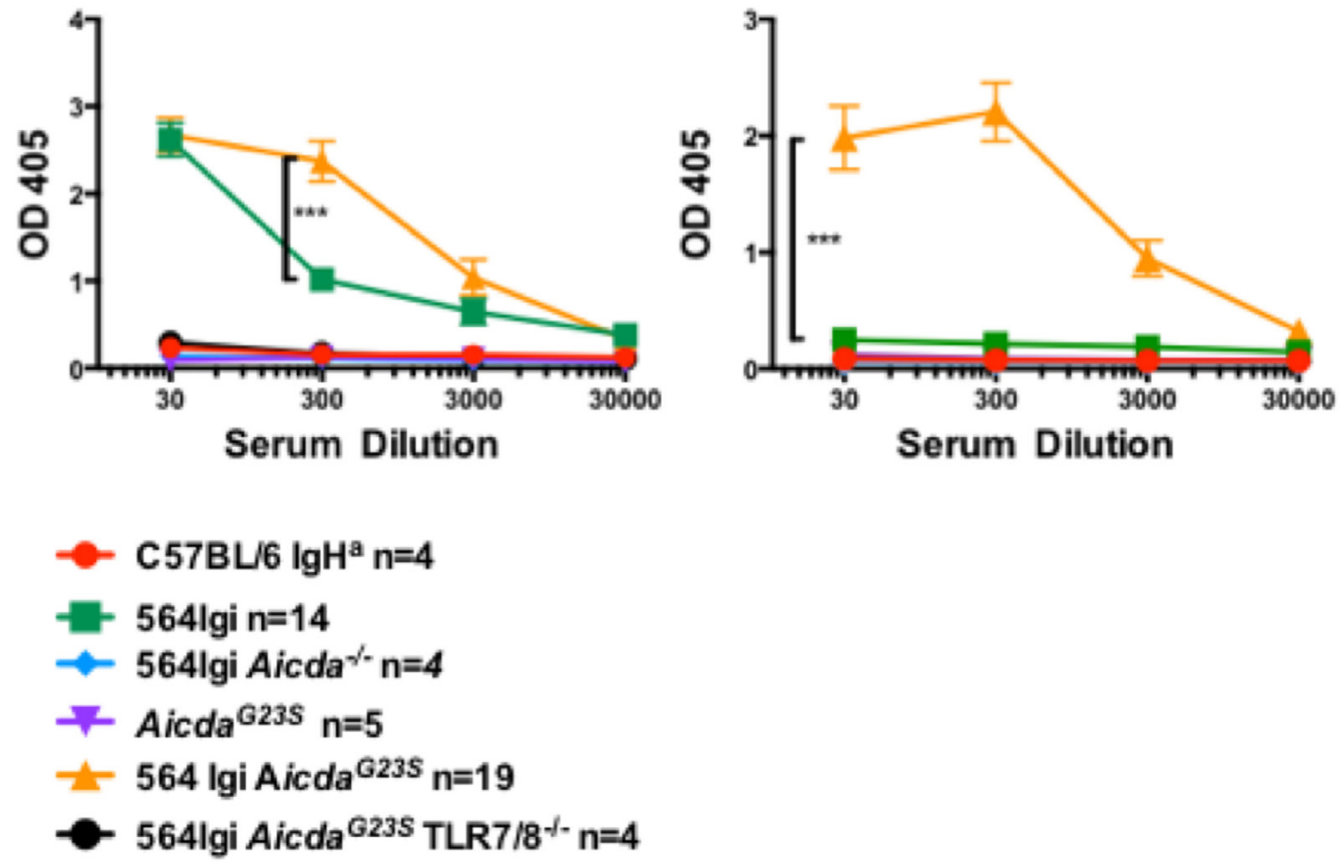

FIGURE 3 | In 564lgi AicdaG23s mice most anti-RNA antibodies (Abs) are IgG2b or IgG1 while in 564lgi mice IgG2a anti-RNA Abs are predominant. (A) HEp-2 anti-nuclear antibody detection assays were performed with sera from the indicated mice and an anti-mouse lgG Alexa-488-labeled antibody. Shown are representative images of C57BL/6J $n=4$, 564lgi $n=6$, 564lgi Aicda ${ }^{\text {G23S }} n=6$ samples. (B-E) Serum anti-RNA Abs were measured by ELISA RNA binding and detection with isotype-specific for $\lg G 2 a(B), \lg G 2 b(\mathbf{C}), \operatorname{lgG} 1$ (D), and IgM (E) anti-RNA Abs. The number of mice in each group is shown in the key. 
immunostaining of cells [Figure 3A; (2)]. As expected, 564Igi and 564Igi $A i c d a^{\mathrm{G} 23 \mathrm{~S}}$ mice had elevated levels of serum anti-RNA IgG2a Abs (Figure 3B); however, 564Igi Aicda ${ }^{\mathrm{G} 23 \mathrm{~S}}$ mice had less IgG2a anti-RNA Abs than 564Igi mice (Figure 3B). This decrease was not due to an overall reduction in serum IgG2a (Figure 2B). On the other hand, serum IgG2b and IgG1 anti-RNA antibody titers were elevated in 564Igi Aicda ${ }^{\mathrm{G} 23 \mathrm{~S}}$ mice (Figures 3C,D). The mechanisms for these shifts in autoantibody isotype are unclear. The expression of IgG2a and IgG2b anti-RNA Abs are still dependent on TLR7/8 expression (Figures 3B,C), as has been reported for 564Igi mice $(2,3,21)$. This is important as it shows that in these mice disease depends on multiple mechanisms and expression of the 564 heavy and light chain genes alone is not sufficient.

\section{Anti-RNA IgG2a Abs in 564lgi but Not 564Igi Aicda ${ }^{\mathrm{G} 23 \mathrm{~s}}$ Mice Are Highly Mutated}

We sequenced Ig genes from hybridomas derived from 564Igi and 564Igi Aicda ${ }^{G 23 S}$ mice secreting anti-RNA IgG Abs. Any hybridoma supernatant that reacted positively with RNA by

A

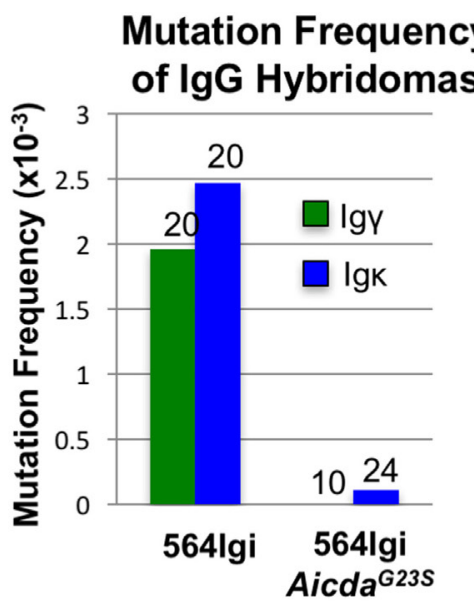

B Distribution of mutations in the IgH and IgL chains of 564Igi anti-RNA IgG2a-producing hybridomas

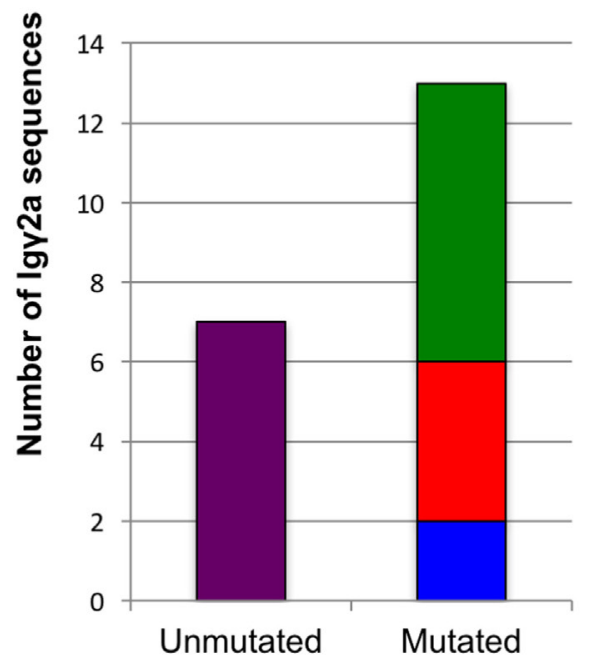

C

\section{Number of Mutations}
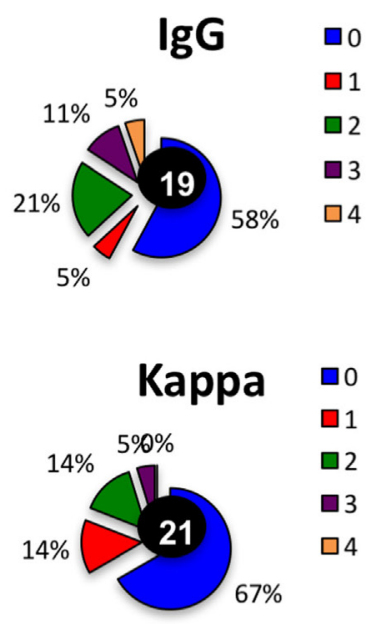

FIGURE 4 | Altered isotype frequencies and reduction of somatic hypermutation in hybridomas derived from 564lgi Aicda ${ }^{\text {G23S }}$ mutant mice Hybridomas were generated from the spleen and bone marrow (BM) of the indicated mice. Hybridoma culture supernatants were tested for IgG anti-RNA antibody secretion by ELISA. (A) The IgH and IgL genes of anti-RNA IgG-producing hybridomas from 564lgi and from 564lgi Aicda ${ }^{\text {G23s }}$ mice were cloned and sequenced. Sequences were compared to the original 564 immunoglobulin knock-in sequences to identify mutations. The mutation frequency is shown. (B) lgr and lgk genes were cloned and sequenced from anti-RNA IgG2a-secreting hybridomas generated from 564lgi spleen and BM cells. Shown is the number of mutated and unmutated sequences.

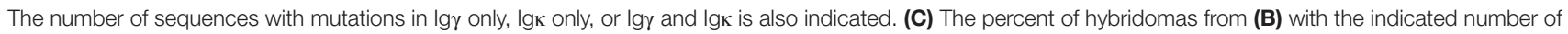
mutations in lgr and lgk genes is shown. The total number of sequences analyzed for each gene is shown in the center. 
ELISA was considered an anti-RNA antibody-secreting hybridoma. Only one of the Ig genes from 564Igi Aicda ${ }^{G 23 S}$-derived hybridomas was found to be mutated (Figure 4A). We suspect that this single mutation is most likely due to PCR error during gene amplification. These data are consistent with reports that Aicda ${ }^{\text {G23S }}$ mice lack SHM (35). On the other hand, we found that $65 \%(13 / 20)$ of anti-RNA IgG-producing hybridomas from 564Igi mice had mutations in IgH, IgL, or both (Figures 4A-C). $\mathrm{IgH}$ genes generally had more mutations per gene than $\operatorname{IgL}$ (Figure 4C). Analyses at the single cells level from 564Igi on a $\mathrm{RAG}^{-/-}$background indicated $50 \%$ of the single cells had mutations (Table 1). We suggest that the germline-encoded self reactivity of the 564Igi knock-in likely induced AID-mediated SHM during B cell development, which in turn then introduced point mutations. We more closely examined the ability of a small number of these Abs to bind RNA and found one example in which anti-RNA binding was drastically reduced compared to the original 564 antibody (Figure S5 in Supplementary Material). This study shows that SHM can result in a tolerance-inducing loss of self reactivity of the 564 antibody.

\section{B Cells in 564lgi Aicda ${ }^{\mathrm{G} 23 s}$ GCs Actively Undergo CSR to IgG1}

In addition to the decrease in anti-RNA IgG2a Abs in 564Igi $A i c d a^{G 23 S}$ compared to 564Igi (Figure 3B), there is a significant increase in anti-RNA IgG1 Abs (Figure 3D) of 564Igi Aicda ${ }^{G 23 S}$. CSR to IgG1 requires T cell help and 564Igi $\mathrm{Rag}^{-/-}$mice, which lack T cells, do not secrete IgG1 Abs (Figure 2B). Therefore, antiRNA IgG1 Abs in 564Igi Aicda ${ }^{G 23 S}$ mice are likely to come from $\mathrm{B}$ cells that have received T cell help in the GC. To examine B cells in the GC, we stained for the presence of $\operatorname{IgG} 1^{+}$cells. 564Igi mice showed some $\mathrm{IgG1}^{+}$cells, but few, if any cells that carry are both $\mathrm{IgG}^{+}$and $\mathrm{IgM}^{+}$, which would indicate active CSR (Figure 5A). 564Igi Aicda ${ }^{G 23 S}$ mice, on the other hand, do have $\operatorname{IgG}^{+} / \mathrm{IgM}^{+}$cells in the GCs (Figure 5A), consistent with the increase in anti-RNA IgG1 Abs compared to 564Igi mice (Figure 3D). However, it has been shown that pathogenic Abs in 564Igi mice are IgG2a Abs that originate from immature B cells in the BM (2), so it is unlikely that the anti-RNA IgG1 Abs found in 564Igi Aicda ${ }^{\text {G23S }}$ mice mediate pathogenesis.

TABLE 1 | Rag-mediated receptor editing in 564lgi Aicda ${ }^{623 S}$ cells.

\begin{tabular}{|c|c|c|c|}
\hline Total Ig $\mu$ sequences & $\begin{array}{l}\text { Mutated } \\
\text { sequences }\end{array}$ & $\begin{array}{l}\text { Unmutated } \\
\text { sequences }\end{array}$ & VH replacements \\
\hline $\begin{array}{l}\text { 564lgi Aicda }{ }^{G 23 S} \\
33\end{array}$ & 0 & 26 & 6 \\
\hline $\begin{array}{l}\text { 564lgi } \mathrm{RAG}^{-/-} \\
45\end{array}$ & 25 & 20 & 0 \\
\hline $\begin{array}{l}564 \operatorname{lgi} \mathrm{Aicda}^{-/-} \\
20\end{array}$ & 0 & 16 & 4 \\
\hline
\end{tabular}

$B 220^{+} B$ cells from the indicated mice were sorted by magnetic negative selection. I $\mu \mu$ DNA sequences were cloned and sequenced from the bulk population and compared to the 564 immunoglobulin knock-in sequence to detect nucleotide exchanges. VH replacements were considered any sequence with more than five mutations in the $\mathrm{VH}$ region.

\section{4lgi Aicda ${ }^{\mathrm{G} 23 \mathrm{~S}}$ GCs Harbor More Idiotype+ B Cells than 564lgi Mice}

It has been shown that GCs in AID-deficient mice and humans are large with proliferating B cells that do not undergo apoptosis $(36,42)$. It has been speculated that is because in the absence of AID; the lack of CSR decreases the amount of DNA damage in the cell and thereby reduces apoptosis (42). To determine if SHM is important for GC expansion, we examined the GC phenotype of 564Igi Aicda ${ }^{G 23 S}$ mice, that exhibit normal frequencies of CSR. We stained splenic GCs for the presence of 564 idiotype $^{+}$B cells. 564Igi Aicda ${ }^{G 23 S}$ mice have many more idiotype ${ }^{+} \mathrm{B}$ cells in the GC compared to 564Igi mice, similar to the phenotype of 564Igi $\mathrm{Aicda}^{-/-}$mice (Figure 5B). This suggests that the lack of SHM, not the lack of CSR, may be responsible for the GC hyperplasia reported in AID-deficient mice and HIGM2 patients.

\section{Igi Aicda ${ }^{\mathrm{G} 23 \mathrm{~S}}$ Females Give Birth to Few Females}

We have previously showed that 564Igi females give birth to litters with high male to female ratios, a phenotype that is largely alleviated if the dams are heterozygous for the $564 \mathrm{IgH}$ and $\mathrm{IgL}$ knock-in genes (43). Furthermore, the purified original IgG2b 564 hybridoma antibody damages developing embryos when injected into pregnant dams, resulting in litters with similarly skewed male:female ratios (43). There have been several reports showing complications during pregnancy in SLE patients (44, 45 ), as well as an increased incidence of cognitive disorders in the offspring born to SLE patients (46-50). In addition, the selective loss of female fetuses in animal models of SLE is due to damage by passage into the fetuses of maternal anti-nucleic acid autoantibodies that cross react with CNS $N$-methyl-D-aspartate receptors, which are more highly expressed in female fetal brains (51-53).

Approximately $35 \%$ of circulating anti-RNA IgG2a Abs in 564Igi mice have the original $564 \mathrm{H}$ and $\mathrm{L}$ chain knock-in sequences (Figure 4B). We suggest that these circulating $564 \mathrm{Abs}$ in 564Igi females may mediate fetal loss. 564Igi Aicda ${ }^{\mathrm{G} 23 \mathrm{~S}}$ mice lack SHM and, therefore, likely have significantly higher titers of the original $564 \mathrm{Abs}$, as supported by the serum anti-RNA antibody analyses (Figure 3) and the sequence analysis of anti-RNA IgG Abs (Figure 4A). Consistent with this hypothesis, 564Igi Aicda ${ }^{\mathrm{G} 23 \mathrm{~S}}$ females yield litters with elevated male:female ratios compared to 564Igi mice, regardless of the genotype of the male partner (Figure 6A, blue and orange), consistent with fetal loss due to maternal anti-nucleotide antibody. However, 564Igi Aicda $a^{\mathrm{G} 23 \mathrm{~S}}$ females that are heterozygous for the G23S mutation (564Igi Aicd $a^{\mathrm{G} 23 \mathrm{~S} /+}$ ), produce litters with male:female ratios approximately equal to 564Igi females (Figure 6A, purple). These data further point to the pathogenicity of anti-RNA Abs and suggest that SHM is a mechanism that prevents the production of autoantibodies that are pathogenic to both the adult and in the developing embryo.

\section{4lgi Aicda ${ }^{\mathrm{G} 23 \mathrm{~S}}$ Mice Suffer from More Severe SLE-Like Disease than 564lgi Mice}

Systemic lupus erythematosus pathogenesis in 564Igi mice has been shown to be mediated by neutrophil activation 

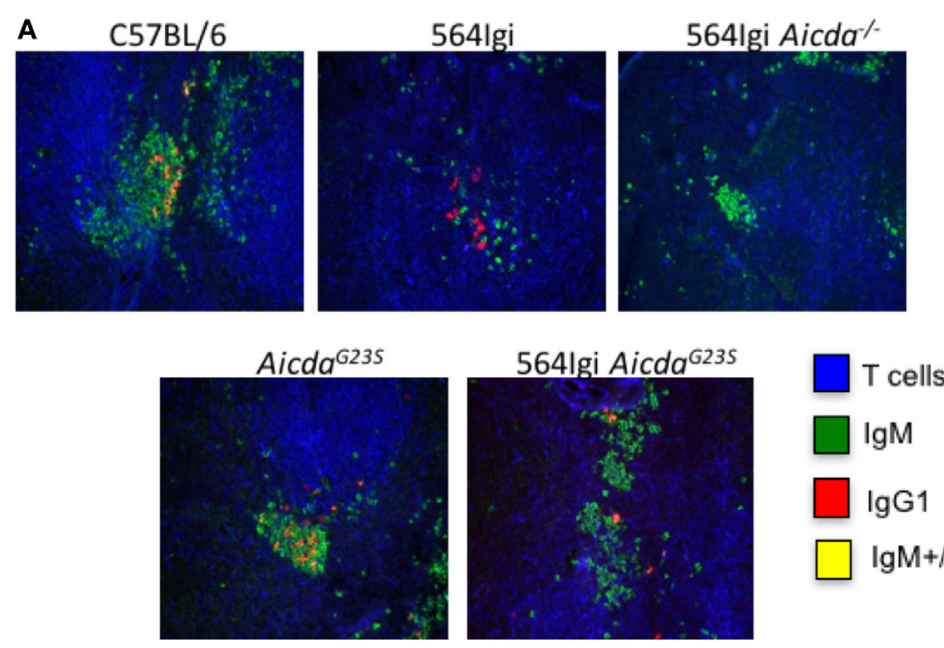

$\square \lg G 1$

$\lg \mathrm{M}+/ \lg \mathrm{g} 1+$
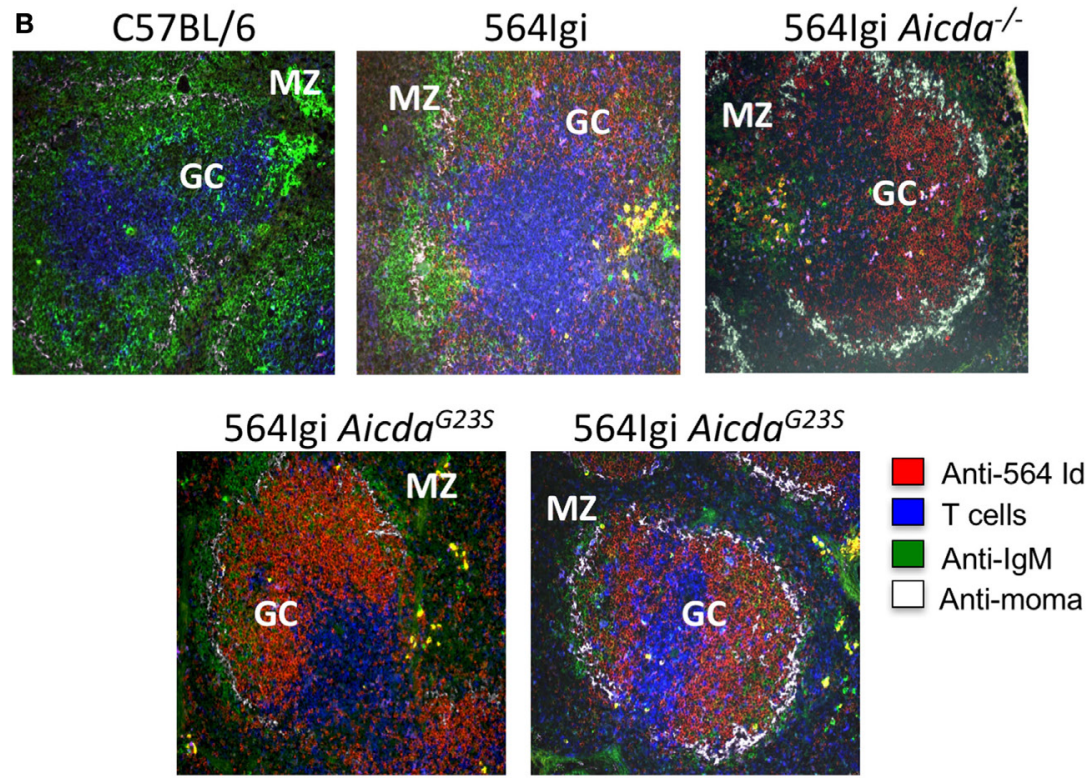

FIGURE 5 | in 564lgi AicdaG23S mice germinal center (GC) B cells actively undergo CSR to IgG1. Spleen samples from the indicated mice were frozen in OCT medium, sectioned, and stained with the indicated antibodies. (A) Spleen sections were stained wit anti-CD4, anti-lgM, and anti-lgG1. Shown is a representative GC from each mouse. A total of three mice were analyzed for each strain. (B) Spleen sections were stained with anti-564 idiotype, anti-CD4, anti-lgM, and MOMA-1. The marginal zone and GC are labeled. Shown is a representative GC from each mouse. A total of two mice were analyzed for each strain.

stimulated by antigen:antibody immunocomplexes (54). 564Igi mice have expanded neutrophil populations and an increase in IFN-I production (54). However, the increase in IFN-I is not the result of increased IFN-I secretion from individual neutrophils, but an increase in the total number of neutrophils secreting IFN-I (54). 564Igi Aicda ${ }^{\mathrm{G} 23 \mathrm{~S}}$ mice have even larger neutrophil populations in the BM than 564Igi mice (Figure 7A).

As they age 564Igi mice also suffer from glomerulonephritis as they age, mediated by immune complex deposition in the renal glomeruli (2). Decreased kidney function is associated with an increase in serum creatinine concentrations. In order to test the degree of tissue damage in 564Igi Aicda ${ }^{\mathrm{G} 23 \mathrm{~S}}$ mice, we measured serum creatinine concentrations as mice aged. 564Igi Aicda ${ }^{\mathrm{G} 23 \mathrm{~S}}$ mice have elevated serum creatinine concentrations compared to 564Igi mice and the difference increases as mice age (Figure 7B). This suggests that 564Igi Aicda ${ }^{\mathrm{G} 23 \mathrm{~S}}$ mice likely suffer from more severe kidney damage when compared to 564Igi mice.

To directly assess immune complex-mediated kidney damage, we stained kidney sections for the presence of 564 idiotype $^{+}$IgG immune complexes. 564Igi mice have many IgG2a/IgG2b immune complexes in the renal glomeruli, but few of these are idiotype ${ }^{+}$ (Figure 7C), likely due to the high level of SHM in anti-RNA IgG Abs (Figure 4). On the other hand, 564Igi Aicda ${ }^{\mathrm{G} 23 \mathrm{~S}}$ mice, on the other hand, have many idiotype ${ }^{+}$IgG2b but no IgG2a immune 


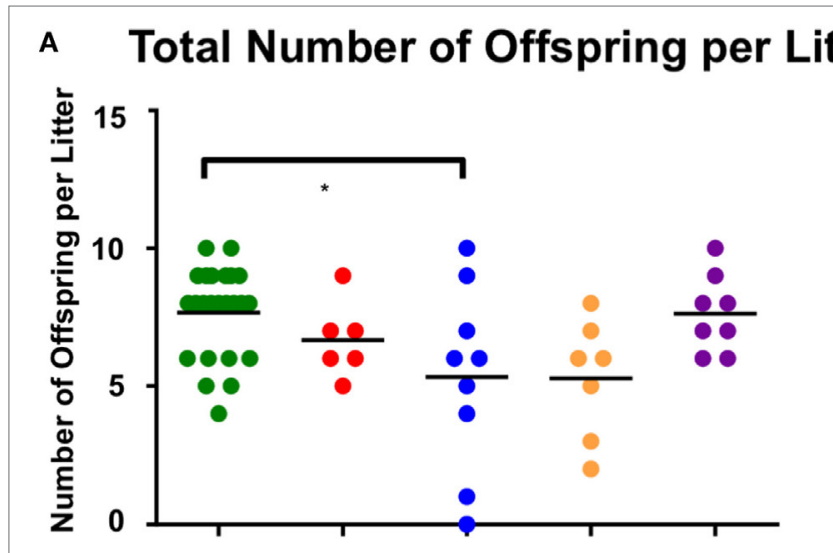

B

Total Number of Male Offspring per Litter

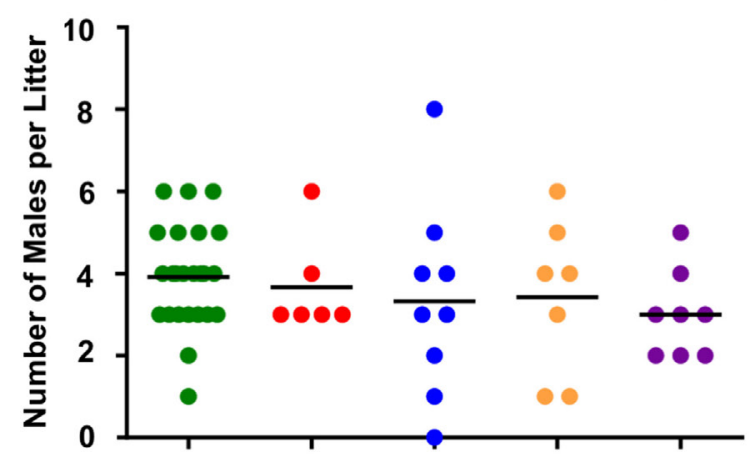

\section{Breeding Pairs}

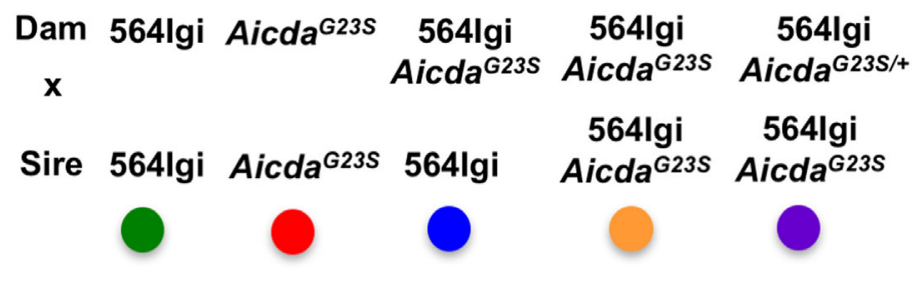

C

Total Number of Female Offspring per Litter

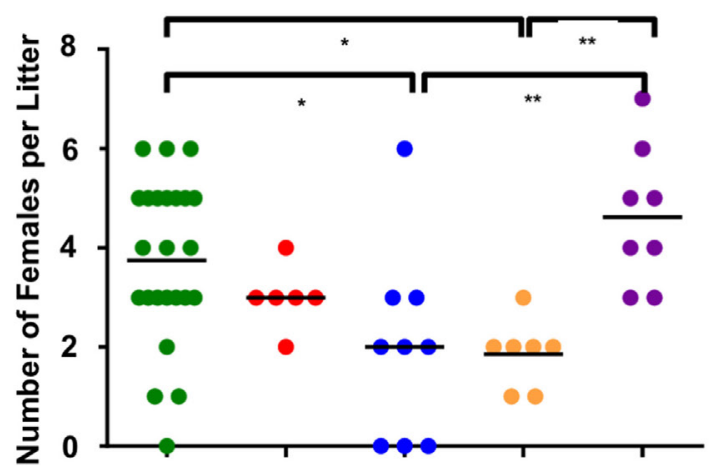

FIGURE 6 | Pregnant 564lgi Aicda ${ }^{\text {G23S }}$ mice deliver fewer female than male offspring. The number of male and female offspring born to the indicated breeding pair were counted, and shown is the (A) total number of offspring, (B) total number of males, and (C) total number of females in each litter. Each data point is an individual litter born to the indicated breeding pair.

complexes in renal glomeruli (Figure 7C), consistent with serum anti-RNA antibody analyses (Figures 3B,C). Ultimately, 564Igi $A i c d a^{\mathrm{G} 23 \mathrm{~S}}$ mice suffer from more severe glomerulonephritis than 564Igi mice (Figure 7D). The glomeruli of 564Igi Aicda ${ }^{\mathrm{G} 23 \mathrm{~S}}$ mice showed an increase in mesangial cell proliferation (Figure 7D, arrow heads), matrix formation (Figure 7D, arrows/dark pink staining), and infiltration of inflammatory cells when compared to 564Igi mice. Young, 4-month-old 564Igi Aicda ${ }^{\text {G23S }}$ mice develop skin lesions not seen in 564Igi mice even when old (Figure 7E). 564Igi Aicd $a^{\mathrm{G} 23 \mathrm{~S}}$ mice eventually succumb to disease more quickly than 564Igi mice (Figure 7F). Taken together, these results indicate that in the 564Igi $A i c d a^{\mathrm{G} 23 \mathrm{~S}}$ model of SLE, SHM is not required for disease and suggest that the lack of SHM actually accelerates pathogenesis.

\section{DISCUSSION}

During development self-reactive B cells with surface IgM can be driven into apoptosis or anergy by ligation with self-antigen (22). However, cells that share the same developmental stage and the same specificity but have IgG rather than IgM receptors are activated by antigenic ligation and, therefore, escape tolerance $(24,25)$. Therefore, because the consequences of ligation of antibody and antigen vary with the isotype of the antibody, AID, by enabling CSR, can enable a self-reactive B cell to escape deletion.

Previously, we showed that production of IgG autoantibody in the 564Igi model of SLE requires expression of activationinduced deaminase in early-developing B cells $(3,21)$. This is not likely to be unique to 564Igi mice as AID is expressed in normal developing B cells in several strains (12). Other reports indicate that SHM can generate autoantibodies (55-57), but it is not yet known if this SHM contributes to the generation of pathogenic autoantibody. Nevertheless, AID through CSR or SHM, can generate autoantibody. Further, prior attempts to demonstrate directly that AID-dependent SHM is crucial for the development of pathogenic autoantibody have been hampered by the utilization of knockout mice in which both SHM and CSR are lost (58). Thus, it is no doubt true that SHM can generate high affinity antiDNA autoantibodies, but care must be taken to not confuse "high affinity" autoantibody with "pathogenic" autoantibody. By the latter, we mean antibody that has been shown to induce pathology when transferred to otherwise normal mice. Also, because the DNA-specific TLR9 acts as a negative regulator of autoantibody production (59-62), it is unlikely that DNA as antigen drives autoimmunity. In fact in the absence of TLR9, MRL/lpr mice 

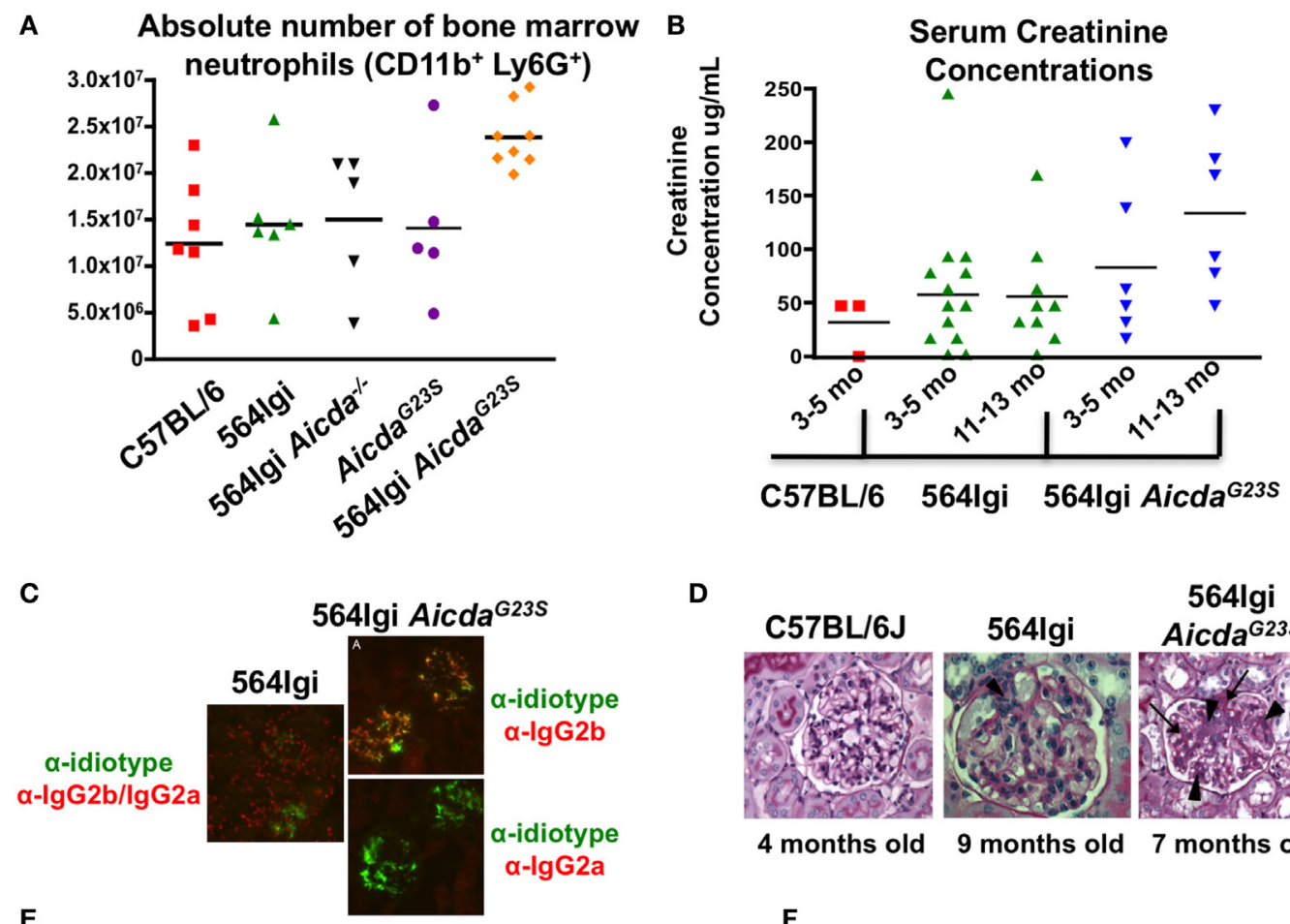

D

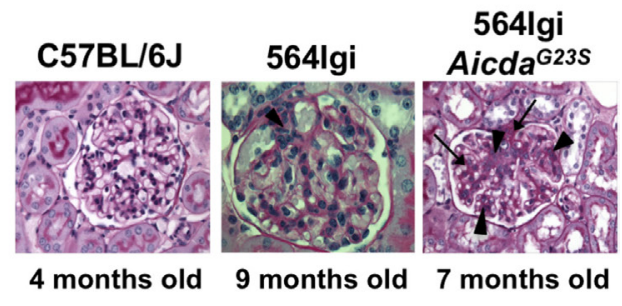

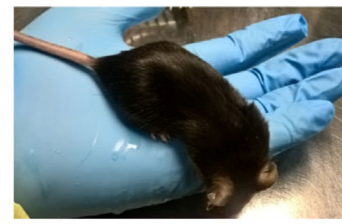

564Igi

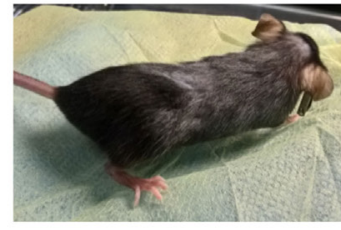

564lgi Aicda ${ }^{G 23 S}$

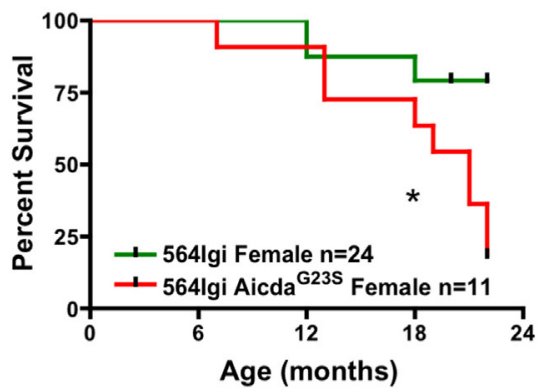

FIGURE 7 | 564lgi Aicda ${ }^{G 23 S}$ mice survive poorly compared to 564lgi mice. (A) Bone marrow cell suspensions were stained with anti-CD11b and anti-Ly6G to detect the presence of neutrophils. The absolute number of neutrophils in from the indicated mice is shown. Each data point represents an individual animal, aged 3-6 months. The mean number of neutrophils is shown with a horizontal line. 564lgi vs 564G23S $p<0.02$. (B) Serum creatinine concentrations were analyzed by ELISA. Shown is the concentration in the indicated mice at various ages. Each data point represents an individual animal. The mean concentration is shown as a horizontal line. 564lgi vs 564G23S p < 0.03. (C) Immunostaining of kidney samples from 564lgi and 564lgi Aicda 2335 mice. IgG2a and lgG2b immune complexes are shown in red and 564 idiotype+ immune complexes are shown in green. Co-staining is seen in yellow. Shown are representative images from two mice per group. (D) $\mathrm{H}$ and $\mathrm{E}$ staining of kidney samples from the indicated mice. The age of each mouse is shown below the image. These are representative images of $n=3$ mice for C57BL/6J, $n=5$ mice for 564lgi and $n=5$ mice for 564lgi Aicda ${ }^{G 23 S}$. (E) Skin lesions typical of 4-month-old 564lgi Aicda ${ }^{623 S}$ mice. Note the loss of hair on the head and the graying of the hair on the body. (F) Kaplan-Meier curve showing the percent survival over time of the indicated mouse strains. The number of mice monitored for each strain is shown in the key. Statistical analysis is based on the log rank test; ${ }^{*} p<0.05$.

make no anti-DNA antibodies, yet there is no mitigation of their severe glomerulonephritis; suggesting that mouse lupus does not require anti-DNA antibodies (59).

Several groups have shown that AID can contribute to the loss of self reactivity in mice and humans $(16,33,34,63,64,65)$. Furthermore, a recent interesting report by Goodnow's group showed that in humans in vivo SHM of germ line genes encoding an autoantibody results in loss of self reactivity (66). These studies did not address whether AID-dependent tolerance actually provides protection against pathogenic antibody. Nor did they show directly that AID-dependent SHM was required.
The studies reported here address these issues directly and AID-dependent SHM is crucial for a B cell tolerance mechanism to limit the secretion of autoantibodies and to prevent the progression of SLE. Yet, at the same time, AID-dependent CSR is required for the production of these pathogenic IgG autoantibodies.

Given this ability to affect the production of autoantibodies, multiple studies have used knockout strategies to address the role of AID in systemic autoimmunity. In MRL/lpr mice, however, the absence of AID results in the production of protective IgM Abs and amelioration of autoimmune disease (67). Thus, the relative 
contribution of SHM and CSR to the generation of autoantibodies in SLE-like disease is unclear.

In the BXD2 model of autoimmunity a dominant negative mutant of Aicda was introduced as a transgene, mitigating the disease (68). However, although the intent was to block only the SHM functions of AID, the mutation compromised class switching and, as a result, the study did not address the original question. In $\mathrm{Aicda}^{-/-} \mathrm{BALB} / \mathrm{c}$ mice, organ-specific but not systemic autoimmunity develops in older animals (69). In MRL/lpr mice with deletion of Aicda there was a significant increase in autoreactive IgM Abs against various antigens, a decrease in IgG Abs to these antigens and a mitigation of disease. Passive transfer of IgM Abs to dsDNA from these mice to otherwise unmanipulated MRL/lpr mice provided protection (70).

Studies in humans agree with the animal model work as they do not provide evidence that the absence of Aicda is sufficient to cause systemic autoimmune disease. While AID-deficient humans with hyper-IgM have an increased risk of autoimmune and inflammatory disorders such as diabetes mellitus, polyarthritis, autoimmune hepatitis, hemolytic anemia, immune thrombocytopenia, Crohn's disease, and chronic uveitis, there is no clear documentation of SLE in these patients (71).

Manifestations of SLE, including glomerulonephritis, are mainly mediated by IgG2a anti-RNA Abs that are produced by $\mathrm{B}$ cells that develop in the BM of 564Igi mice (2). Here, we show that in 564Igi Aicda ${ }^{\mathrm{G} 23 \mathrm{~S}}$ mice disease is also mediated by IgG2a/ IgG2b Abs. These Ig subclasses bind the activating Fc receptors, Fc $\gamma$ RIV (IgG2a and IgG2b); Fc $\gamma$ RI (IgG2a only) with high affinity (72). IgG1, on the other hand, binds only the Fc receptor FcyRIII (73) with low affinity. Thus, all activating mouse Fc $\gamma$ Rs (FcyRI, FcyRIII, and FcyRIV) bind to IgG2a and IgG2b, whereas FcyRIII

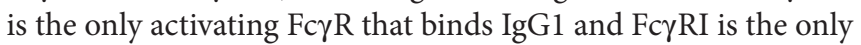
activating Fc $\gamma \mathrm{R}$ that binds IgG3. The production of IgG1 requires $\mathrm{T}$ cell help and is, therefore, only produced by mature B cells in the GC. Therefore, the most pathogenic Abs in 564Igi Aicda ${ }^{\mathrm{G} 23 \mathrm{~S}}$ mice are likely to be IgG2a/IgG2b Abs produced by developing $\mathrm{B}$ cells. Because IgG1 does not bind activating FcR we believe that it does not contribute to the pathology.

FcyRIIb, the inhibitory Fc receptor, induces pro-apoptotic signals in mature B cells, acting as a peripheral tolerance mechanism. However, co-ligation of FcyRIIb and the BCR by a high affinity antigen-antibody complex may bypass apoptotic signals and initiate positive selection of those cells in the GC (74). In the BM of 564Igi and 564Igi Aicda ${ }^{\mathrm{G} 23 \mathrm{~S}}$ mice, the presence of selfreactive Abs likely induces Aicda expression, as described above. In 564Igi mice, AID-mediated SHM may decrease the affinity of the BCR for antigen. In combination with FcyRIIb engagement by IgG2a Abs produced by BM B cells, many self-reactive cells likely undergo apoptosis. However, in 564Igi Aicda ${ }^{\mathrm{G} 23 \mathrm{~S}}$ mice, the lack of SHM causes a higher affinity of the BCR for antigen, which in combination with FcyRIIb engagement induces a stimulatory signal to further increase autoantibody production.

Previous reports have shown that the Aicda ${ }^{G 23 S}$ mutation results in increased bacterial load in the small intestine of naïve mice (35). In addition, the Aicd $a^{G 23 S}$ mutation decreases survival of mice orally challenged with cholera toxin and increases the bacterial load of mesenteric lymph nodes of mice fed
Y. enterocolitica, correlating SHM with the capacity to protect the mucosa (35). To avoid the impact of an altered microbiome on our experiments, the mice were placed on oral Uniprim, which contains sulfadiazine and trimethoprim. However, the effect of microbial load on the survival of naïve $A i c d a^{G 23 S}$ mice has not been examined. We did not see evidence of disease in Aicda ${ }^{\mathrm{G} 23 \mathrm{~S}}$ mice that did not carry $564 \mathrm{H}$ and L chain gene knock-ins.

It has been shown that antibody constant regions can also impact antibody pathogenicity (75). This suggests that the fine affinities of the IgG2a/IgG2b/IgG1 anti-RNA Abs may vary slightly due to differences in the constant regions and affect the pathogenesis of SLE in 564Igi and 564Igi Aicda ${ }^{\mathrm{G} 23 \mathrm{~S}}$ mice. The receptors in 564Igi $A i c d a^{\mathrm{G} 23 \mathrm{~S}}$ mice may have a higher affinity for RNA in vivo, which causes the B cell to become activated, to migrate to the GC and to undergo CSR to IgG1 with T cell help. In 564Igi mice, on the other hand, the introduction of nucleotide exchanges in anti-RNA receptors may alter antibody affinity and/or specificity for antigen in vivo, promoting the selection of IgG2 $\mathrm{a}^{+}$cells in a T cell-independent manner. These mutated Abs may be less pathogenic in vivo compared to the original Abs in 564Igi Aicda ${ }^{\mathrm{G} 23 \mathrm{~S}}$ mice, allowing 564Igi mice to survive longer. This hypothesis is supported by the fact that circulating maternal Abs in 564Igi females seem to be less pathogenic than those in 564Igi Aicda ${ }^{\mathrm{G} 23 \mathrm{~S}}$ females (Figure 6).

In sum, in the 564Igi mice, the loss of SHM results in more severe autoimmunity and early death, suggesting that AID can mitigate autoantibody production by altering antibody specificity.

\section{EXPERIMENTAL PROCEDURES}

\section{Mice}

All experiments with mice were performed in accordance with the regulations of and with the approval off the Tufts/TMC IACUC (protocol B2015-41). Creation of the 564Igi mice was previously described (2). 564Igi mice have knocked-in $\mathrm{H}$ and $\mathrm{L}$ chain genes of the 564 hybridoma derived from an (SWRxNZB) $\mathrm{F}_{1}$, mouse, a known model of SLE. The H chain of 564 has three nucleotide replacements, none in the CDRs, compared to the germ line of SWR (76). The $564 \mathrm{~L}$ chain gene has two nucleotide replacements, in the CDR2 when compared to 45-21.1 $(76,77)$. All 564Igi mice are homozygous for the $564 \mathrm{IgH}$ and IgL alleles unless otherwise indicated. $A i c d a^{-/-}$and $A i c d a^{G 23 S}$ mice were obtained from Dr. T. Honjo (Kyoto University, Japan). C57BL/6, $\mathrm{C} 57 \mathrm{BL} / 6 \mathrm{IgH}^{\mathrm{a}}$, and $\mathrm{Rag}^{-/-}$mice were purchased from Jackson Laboratories. All mice were genotyped by Transnetyx Inc. Experiments were performed with male and female mice unless otherwise indicated. All mice in this study were maintained on a diet that included Uniprim ${ }^{\circledR}$, a combination of sulfadiazine and trimethoprim, to prevent an expansion of microflora in the small intestine as seen in untreated mice expressing the G23S mutant form of AID (35).

\section{qRT-PCR}

RNA was isolated from cells by TRIzol incubation (Life Technologies 15596) followed by chloroform extraction. All RT-qPCR experiments were performed using two fourfold serial dilutions of RNA and iScript Reverse Transcription Supermix for 
RT-qPCR from Bio-Rad (170-8841). Triplicate cDNA samples were used for the amplification of $A c t b$ and Aicda using commercially available FAM primer probes (Life Technologies) and a Bio-Rad IQ5 quantitative PCR system. Gene expression was normalized to $A c t b$ expression based on a standard curve.

\section{Cloning and Sequencing}

Sequencing was performed as previously described (21). Briefly, single $\mathrm{CD} 138^{+}$cell or a population of $\mathrm{B} 220^{+}$cells were sorted by flow cytometry. RNA was isolated and converted into cDNA using the SuperScript III First Strand Synthesis System (ThermoFisher 18080051) or TRIZOL reagent followed by the iScript cDNA Synthesis Kit (BioRad 170-8890), for single cells and cell populations, respectively. Ig genes were then amplified, cloned, and expressed as described (21).

\section{ELISAs}

\section{Total Isotype/Anti-RNA}

ELISAs were performed as previously described (21).

\section{Serum Creatinine}

Serum creatinine concentrations were determined using a commercially available kit from Abcam (ab65340) following the manufacturer's protocol.

\section{Hybridomas}

Spleen- or BM-derived mouse cells were fused with the P3X63Ag8.653 mouse myeloma cell line (78). Cells were grown in 96-well culture plates in media to select for the growth of successfully fused cells (15\% FCS, 10\% hypoxanthine and 10\% azaserine RPMI complete media). After 2 weeks, culture supernatants from healthy hybridomas were collected and tested for antibody production by ELISA and cells were collected for cloning and sequencing.

\section{Flow Cytometry}

Cells were stained for flow cytometry according to standard procedures. Single cell suspensions were diluted to $1 \times 10^{6}$ cells $/ \mathrm{mL}$ in FACS staining buffer ( $1 \%$ heat-inactivated rabbit serum $/ 0.1 \%$ $\mathrm{NaN}_{3} / 1 \times$ DPBS with $\mathrm{Ca}^{++} \mathrm{Mg}^{++}$). Cells were centrifuged and resuspended in $50 \mu \mathrm{L}$ of fluorescent Abs (Southern Biotech and Biolegend) diluted to $1 \mu \mathrm{g} / \mathrm{mL}$ in FACS staining buffer. Samples were washed in $2 \mathrm{~mL}$ FACS staining buffer and resuspended in $500 \mu \mathrm{L}$ FACS staining buffer for analysis. Propidium iodide was added to a final concentration of $10 \mathrm{ng} / \mathrm{mL}$ just prior to analysis on a FACScalibur flow cytometer (BD Biosciences) to assess cell viability.

\section{HEp-2}

Anti-nuclear Abs were detected by HEp-2 staining according to the manufacturer's protocol (MBL Bion ANK-120).

\section{Immunofluorescence and Light Microscopy}

Fresh kidney or spleen samples for immunofluorescence studies were frozen in OCT medium. $4 \mu \mathrm{m}$ sections were cut on a cryostat and mounted on a glass slide. The sections were air dried for $1 \mathrm{~h}$, rehydrated in PBS, and incubated with anti-IgG2a/IgG2b/ IgG1/IgM, anti-CD4, anti-MOMA, and anti-idiotype Abs for $1 \mathrm{~h}$ at room temperature. The sections were rinsed again in PBS, mounted in Fluoromount (Southern Biotech), and examined and photographed with a Leica fluorescence microscope. For light microscopy studies, fresh kidneys were fixed in $10 \%$ buffered formalin and embedded in paraffin. $5 \mu \mathrm{m}$ paraffin sections were stained with periodic acid-Schiff and evaluated by light microscopy.

\section{Statistical Analysis}

The $p$ values were calculated using one-way ANOVA for all analyses, followed by the Tukey multiple comparison test unless otherwise indicated (Prism GraphPad Software). For all figures ${ }^{*} p<0.05,{ }^{* *} p<0.01$, and ${ }^{* *} p<0.001$.

\section{ETHICS STATEMENT}

All experiments with mice were performed in accordance with the regulations of and with the approval of the Tufts/TMC IACUC (protocol B2012-41).

\section{AUTHOR CONTRIBUTIONS}

GM designed the study with TI-K and carried out experiments, some of them with CM, did statistical evaluations, analyzed the data, and wrote the manuscript; MP was responsible for histology and analysis of pathology in Kidneys and spleens. CM with GM performed experiments with single cells, cloned and sequenced $\mathrm{H}$ and $\mathrm{L}$ chain genes, and expressed functional $\mathrm{H}$ and $\mathrm{l}$ chain genes. Analyzed data with GM and TI-K. JK did immunocytochemistry and fluorescent analysis of spleen and kidney sections of mice. RS was responsible for the generation of Aicda-mutant mice. TH was responsible for the idea and creation of Aicda mutant mice unable to SHM Ig genes, but capable of CSR. ES together with TI-K and GM was involved in the design and critical analysis of the data. GM and TI-K wrote the manuscript, and ES and HW critically reviewed the data and added comments and revised the manuscript.

\section{ACKNOWLEDGMENTS}

The authors would like to thank Dr. Robert Berland for critical review of our manuscript. The authors also thank Carly Warehan for valuable technical assistance. The authors would like to thank Allen Parmalee and Steven Kwok for their help and support purifying cell populations and FACS analysis. The authors thank the Eshe Fund for their generous support. This work was supported by National Institutes of Health grants AI076409 (TI-K), AI24465 (ES), and AI14782-38 (JK).

\section{SUPPLEMENTARY MATERIAL}

The Supplementary Material for this article can be found online at http://journal.frontiersin.org/article/10.3389/fimmu.2017.01094/ full\#supplementary-material. 


\section{REFERENCES}

1. Kirou KA, Lee C, George S, Louca K, Person MG, Crow MK. Activation of the interferon-alpha pathway identifies a subgroup of systemic lupus erythematosus patients with distinct serologic features and active disease. Arthritis Rheum (2005) 52:1491-503. doi:10.1002/art.21031

2. Berland R, Fernandez L, Kari E, Han JH, Lomakin I, Akira S, et al. Toll-like receptor 7-dependent loss of $\mathrm{B}$ cell tolerance in pathogenic autoantibody knockin mice. Immunity (2006) 25:429-40. doi:10.1016/j. immuni.2006.07.014

3. Umiker BR, Andersson S, Fernandez L, Korgaokar P, Larbi A, Pilichowska M, et al. Dosage of X-linked toll-like receptor 8 determines gender differences in the development of systemic lupus erythematosus. Eur J Immunol (2014) 44:1503-16. doi:10.1002/eji.201344283

4. Goodnow CC, Crosbie J, Adelstein S, Lavoie TB, Smith-Gill SJ, Brink RA, et al. Altered immunoglobulin expression and functional silencing of selfreactive B lymphocytes in transgenic mice. Nature (1988) 334(6184):676-82. doi:10.1038/334676a0

5. Nemazee DA, Burki K. Clonal deletion of B lymphocytes in a transgenic mouse bearing anti-MHC class I antibody genes. Nature (1989) 337(6207):562-6. doi:10.1038/337562a0

6. Chen C, Nagy Z, Prak EL, Weigert M. Immunoglobulin heavy chain gene replacement: a mechanism of receptor editing. Immunity (1995) 3(6):747-55.

7. Nemazee D, Weigert M. Revising B cell receptors. J Exp Med (2000) 191(11): 1813-7. doi:10.1084/jem.191.11.1813

8. Zhang Z, Zemlin M, Wang YH, Munfus D, Huye LE, Findley HW, et al. Contribution of Vh gene replacement to the primary B cell repertoire. Immunity (2003) 19(1):21-31. doi:10.1016/S1074-7613(03)00170-5

9. Muramatsu M, Sankaranand VS, Anant S, Sugai M, Kinoshita K, Davidson NO, et al. Specific expression of activation-induced cytidine deaminase (AID), a novel member of the RNA-editing deaminase family in germinal center B cells. J Biol Chem (1999) 274:18470-6. doi:10.1074/jbc.274.26.18470

10. Weller S, Faili A, Garcia C, Braun MC, Le Deist FF, de Saint Basile GG, et al. CD40-CD40L independent Ig gene hypermutation suggests a second B cell diversification pathway in humans. Proc Natl Acad Sci U S A (2001) 98(3):1166-70. doi:10.1073/pnas.98.3.1166

11. Mao C, Jiang L, Melo-Jorge M, Puthenveetil M, Zhang X, Carroll MC, et al. $\mathrm{T}$ cell-independent somatic hypermutation in murine $\mathrm{B}$ cells with an immature phenotype. Immunity (2004) 20(2):133-44. doi:10.1016/S10747613(04)00019-6

12. Han JH, Akira S, Calame K, Beutler B, Selsing E, Imanishi-Kari T. Class switch recombination and somatic hypermutation in early mouse B cells are mediated by B cell and toll-like receptors. Immunity (2007) 27:64-75. doi:10.1016/ j.immuni.2007.05.018

13. Ueda Y, Liao D, Yand K, Patel A, Kelsoe G. T-independent activation-induced cytidine deaminase expression, class-switch recombination, and antibody production by immature/transitional 1 B cells. J Immunol (2007) 178:3592-601. doi:10.4049/jimmunol.178.6.3593

14. Wesemann DR, Magee JM, Boboila C, Calado DP, Gallagher MP, Portuguese AJ, et al. Immature B cells preferentially switch to IgE with increased direct $\mathrm{S} \mu$ to $\mathrm{S} \varepsilon$ recombination. J Exp Med (2011) 208(13):2733-46. doi:10.1084/jem.20111155

15. Kumar S, Wuerffel R, Achour I, Lajoie B, Sen R, Dekker J, et al. Flexible ordering of antibody class switch and V(D)J joining during B-cell ontogeny. Genes Dev (2013) 27(22):2439-44. doi:10.1101/gad.227165.113

16. Cantaert T, Schickel JN, Bannock JM, Ng YS, Massad C, Delmotte FR, et al. Decreased somatic hypermutation induces an impaired peripheral B cell tolerance checkpoint. J Clin Invest (2016) 126(11):4289-302. doi:10.1172/ JCI84645

17. Suurmond J, Calise J, Malkiel S, Diamond B. DNA-reactive B cells in lupus. Curr Opin Immunol (2016) 43:1-7. doi:10.1016/j.coi.2016.07.002

18. Förger F, Matthias T, Oppermann M, Becker H, Helmke K. Clinical significance of anti-dsDNA antibody isotypes: IgG/IgM ratio of anti-dsDNA antibodies as a prognostic marker for lupus nephritis. Lupus (2004) 13(1):36-44. doi:10.1191/0961203304lu485oa

19. Clynes R, Dumitru C, Ravetch JV. Uncoupling of immune complex formation and kidney damage in autoimmune glomerulonephritis. Science (1998) 279:1052-4. doi:10.1126/science.279.5353.1052
20. Raz E, Brezis M, Rosenmann E, Eilat D. Anti-DNA antibodies bind directly to renal antigens and induce kidney dysfunction in the isolated perfused rat kidney. J Immunol (1989) 142:3076-82.

21. Umiker B, McDonald G, Larbi A, Medina C, Hobeika E, Reth M, et al Production of pathogenic IgG autoantibody requires expression of activation induced deaminase in developing B cells. Eur J Immunol (2014) 44:3093-108. doi:10.1002/eji.201344282

22. Rolink AG, Schaniel C, Andersson J, Melchers F. Selection events operating at various stages in B cell development. Curr Opin Immunol (2001) 13(2):202-7. doi:10.1016/S0952-7915(00)00205-3

23. von Boehmer H, Melchers F. Checkpoints in lymphocyte development and autoimmune disease. Nat Immunol (2010) 11(1):14-20. doi:10.1038/ni.1794

24. Horikawa K, Martin SW, Pogue SL, Silver K, Peng K, Takatsu K, et al. Enhancement and suppression of signaling by the conserved tail of IgG memory-type B cell antigen receptors. J Exp Med (2007) 204(4):759-69. doi:10.1084/jem.20061923

25. Waisman A, Kraus M, Seagal J, Ghosh S, Melamed D, Song J, et al. IgG1 B cell receptor signaling is inhibited by $\mathrm{CD} 22$ and promotes the development of B cells whose survival is less dependent on Ig alpha/beta. J Exp Med (2007) 204(4):747-58. doi:10.1084/jem.20062024

26. Leadbetter EA, Rifkin IR, Hohlbaum AM, Beaudette BC, Shlomchik MJ, Marshak-Rothstein A. Chromatin-IgG complexes activate B cells by dual engagement of IgM and toll-like receptors. Nature (2002) 416(6881):603-7. doi:10.1038/416603a

27. Lau CM, Broughton C, Tabor AS, Akira S, Flavell RA, Mamula MJ, et al. RNAassociated autoantigens activate B cells by combined B cell antigen receptor/ toll-like receptor 7 engagement. J Exp Med (2005) 202(9):1171-7. doi:10.1084/ jem. 20050630

28. Pone EJ, Zhang J, Mai T, White CA, Li G, Sakakura JK, et al. BCR-signalling synergizes with TLR-signalling for induction of AID and immunoglobulin class-switching through the non-canonical NF- $\mathrm{B}$ pathway. Nat Commun (2012) 3:767. doi:10.1038/ncomms1769

29. Giltiay NV, Chappell CP, Sun X, Kolhatkar N, Teal TH, Wiedeman AE, et al. Overexpression of TLR7 promotes cell-intrinsic expansion and autoantibody production by transitional T1 B cells. J Exp Med (2013) 210:2773-89. doi:10.1084/jem.20122798

30. Hepburn AL, Lampert IA, Boyle JJ, Horncastle D, Ng WF, Layton M, et al. In vivo evidence for apoptosis in the bone marrow in systemic lupus erythematosus. Ann Rheum Dis (2007) 66(8):1106-9. doi:10.1136/ard.2006. 065003

31. Wardemann H, Yurasov S, Schaefer A, Young JW, Meffre E, Nussenzweig MC. Predominant autoantibody production by early human B cell precursors. Science (2003) 301:1374-7. doi:10.1126/science.1086907

32. Blasius AL, Beutler B. Intracellular toll-like receptors. Immunity (2010) 32(3):305-15. doi:10.1016/j.immuni.2010.03.012

33. Kuraoka M, Holl TM, Liao D, Womble M, Cain DW, Reynolds AE, et al. Activation-induced cytidine deaminase mediates central tolerance in B cells. Proc Natl Acad Sci U S A (2011) 108:11560-5. doi:10.1073/ pnas. 1102571108

34. Cantaert T, Schickel JN, Bannock JM, Ng YS, Massad C, Oe T, et al. Activationinduced cytidine deaminase expression in human B cell precursors is essential for central B cell tolerance. Immunity (2015) 43(5):884-95. doi:10.1016/j. immuni.2015.10.002

35. Wei M, Shinkura R, Doi Y, Maruya M, Fagarasan S, Honjo T. Mice carrying a knock-in mutation of Aicda resulting in a defect in somatic hypermutation have impaired gut homeostasis and compromised mucosal defense. Nat Immunol (2011) 12:264-70. doi:10.1038/ni.1991

36. Muramatsu M, Kinoshita K, Fagarasan S, Yamada S, Shinkai Y, Honjo T. Class switch recombination and hypermutation require activation-induced cytidine deaminase (AID), a potential RNA editing enzyme. Cell (2000) 102:553-63. doi:10.1016/S0092-8674(00)00078-7

37. Aoufouchi S, Faili A, Zober C, D'Orlando O, Weller S, Weill JC, et al. Proteasomal degradation restricts the nuclear lifespan of AID. J Exp Med (2008) 205:1357-68. doi:10.1084/jem.20070950

38. Hasler J, Rada C, Neuberger MS. Cytoplasmic activation-induced cytidine deaminase (AID) exists in stoichiometric complex with translation elongation factor lalpha (eEF1A). Proc Natl Acad Sci U S A (2011) 108:18366-71. doi:10.1073/pnas.1106729108 
39. Li G, Pone EJ, Tran DC, Patel PJ, Dao L, Xu Z, et al. Iron inhibits activationinduced cytidine deaminase enzymatic activity and modulates immunoglobulin class switch DNA recombination. J Biol Chem (2012) 287:21520-9. doi:10.1074/jbc.M112.366732

40. Muto T, Okazaki IM, Yamada S, Tanaka Y, Kinoshita K, Muramatsu M, et al. Negative regulation of activation-induced cytidine deaminase in B cells. Proc Natl Acad Sci U S A (2006) 103:2752-7. doi:10.1073/pnas.0510970103

41. Uchimura Y, Barton LF, Rada C, Neuberger MS. REG-gamma associates with and modulates the abundance of nuclear activation-induced deaminase. J Exp Med (2011) 208:2385-91. doi:10.1084/jem.20110856

42. Zaheen A, Boulianne B, Parsa JY, Ramachandran S, Gommerman JL, Martin A. AID constrains germinal center size by rendering B cells susceptible to apoptosis. Blood (2009) 114:547-54. doi:10.1182/blood-2009-03211763

43. McDonald G, Cabal N, Vannier A, Umiker B, Yin RH, Orjalo AV Jr, et al. Female bias in systemic lupus erythematosus is associated with the differential expression of X-linked toll-like receptor 8. Front Immunol (2015) 6:457. doi:10.3389/fimmu.2015.00457

44. Clark CA, Spitzer KA, Laskin CA. Decrease in pregnancy loss rates in patients with systemic lupus erythematosus over a 40-year period. J Rheumatol (2005) 32(9):1709-12.

45. Smyth A, Oliveira GH, Lahr BD, Bailey KR, Norby SM, Garovic VD. A systematic review and meta-analysis of pregnancy outcomes in patients with systemic lupus erythematosus and lupus nephritis. Clin J Am Soc Nephrol (2010) 5(11):2060-8. doi:10.2215/CJN.00240110

46. Lahita RG. Systemic lupus erythematosus: learning disability in the male offspring of female patients and relationship to laterality. Psychoneuroendocrinology (1988) 13(5):385-96. doi:10.1016/0306-4530(88)90045-5

47. Lee JY, Huerta PT, Zhang J, Kowal C, Bertini E, Volpe BT, et al. Neurotoxic autoantibodies mediate congenital cortical impairment of offspring in maternal lupus. Nat Med (2009) 15(1):91-6. doi:10.1038/nm.1892

48. McAllister DL, Kaplan BJ, Edworthy SM, Martin L, Crawford SG, RamseyGoldman R, et al. The influence of systemic lupus erythematosus on fetal development: cognitive, behavioral, and health trends. J Int Neuropsychol Soc (1997) 3(4):370-6.

49. Neri F, Chimini L, Bonomi F, Filippini E, Motta M, Faden D, et al. Neuropsychological development of children born to patients with systemic lupus erythematosus. Lupus (2004) 13(10):805-11. doi:10.1191/ 0961203304lu2018oa

50. Ross G, Sammaritano L, Nass R, Lockshin M. Effects of mothers' autoimmune disease during pregnancy on learning disabilities and hand preference in their children. Arch Pediatr Adolesc Med (2003) 157(4):397-402. doi:10.1001/ archpedi.157.4.397

51. Wang L, Zhou D, Lee J, Niu H, Faust TW, Frattini S, et al. Female mouse fetal loss mediated by maternal autoantibody. J Exp Med (2012) 209(6):1083-9. doi:10.1084/jem.20111986

52. Tincani A, Danieli E, Nuzzo M, Scarsil M, Motta M, Cimaz R, et al. Impact of in utero environment on the offspring of lupus patients. Lupus (2006) 15(11):801-7. doi:10.1177/0961203306071005

53. DeGiorgio LA, Konstantinov KN, Lee SC, Hardin JA, Volpe BT, Diamond B. A subset of lupus anti-DNA antibodies cross-reacts with the NR2 glutamate receptor in systemic lupus erythematosus. Nat Med (2001) 7(11):1189-93. doi:10.1038/nm1101-1189

54. Han JH, Umiker BR, Kazimirova AA, Fray M, Korgaonkar P, Selsing E, et al. Expression of an anti-RNA autoantibody in a mouse model of SLE increases neutrophil and monocyte numbers as well as IFN-I expression. Eur J Immunol (2014) 44:215-26. doi:10.1002/eji.201343714

55. Shlomchik MJ, Marshak-Rothstein A, Wolfowicz CB, Rothstein TL, Weigert MG. The role of clonal selection and somatic mutation in autoimmunity. Nature (1987) 328:805-11. doi:10.1038/328805a0

56. Brard F, Shannon M, Prak EL, Litwin S, Weigert M. Somatic mutation and light chain rearrangement generate autoimmunity in anti-single-stranded DNA transgenic MRL/lpr mice. J Exp Med (1999) 190(5):691-704. doi:10.1084/ jem.190.5.691

57. Guo W, Smith D, Aviszus K, Detanico T, Heiser RA, Wysocki LJ. Somatic hypermutation as a generator of antinuclear antibodies in a murine model of systemic autoimmunity. J Exp Med (2010) 207:2225-37. doi:10.1084/ jem.20092712
58. Detanico T, Guo W, Wysocki LJ. Predominant role for activation-induced cytidine deaminase in generating IgG anti-nucleosomal antibodies of murine SLE. J Autoimmun (2015) 58:67-77. doi:10.1016/j.jaut.2015.01.006

59. Christensen SR, Kashgarian M, Alexopoulou L, Flavell RA, Akira S, Shlomchik MJ. Toll-like receptor 9 controls anti-DNA autoantibody production in murine lupus. J Exp Med (2005) 202:321-31. doi:10.1084/jem.20050338

60. Christensen SR, Shupe J, Nickerson K, Kashgarian M, Flavell RA, Shlomchik MJ. Toll-like receptor 7 and TLR9 dictate autoantibody specificity and have opposing inflammatory and regulatory roles in a murine model of lupus. Immunity (2006) 25:417-28. doi:10.1016/j.immuni.2006.07.013

61. Wu X, Peng SL. Toll-like receptor 9 signaling protects against murine lupus. Arthritis Rheum (2006) 54:336-42. doi:10.1002/art.21553

62. Lartigue A, Courville P, Auquit I, Francois A, Arnoult C, Tron F, et al. Role of TLR9 in anti-nucleosome and anti-DNA antibody production in lpr mutation-induced murine lupus. J Immunol (2006) 177:1349-54. doi:10.4049/ jimmunol.177.2.1349

63. Meyers G, Ng YS, Bannock JM, Lavoie A, Walter JE, Notarangelo LD, et al. Activation-induced cytidine deaminase (AID) is required for B-cell tolerance in humans. Proc Natl Acad Sci U S A (2011) 108:11554-9. doi:10.1073/ pnas. 1102600108

64. Sabouri Z, Schofield P, Horikawa K, Spierings E, Kipling D, Randall KL, et al. Redemption of autoantibodies on anergic B cells by variable-region glycosylation and mutation away from self-reactivity. Proc Natl Acad Sci U S A (2014) 111(25):E2567-75. doi:10.1073/pnas.1406974111

65. Kuraoka M, Snowden PB, Nojima T, Verkoczy L, Haynes BF, Kitamura D, et al. BCR and endosomal TLR signals synergize to increase AID expression and establish central B cell tolerance. Cell Rep (2017) 18(7):1627-35. doi:10.1016/ j.celrep.2017.01.050

66. Reed JH, Jackson J, Christ D, Goodnow CC. Clonal redemption of autoantibodies by somatic hypermutation away from self-reactivity during human immunization. J Exp Med (2016) 213(7):1255-65. doi:10.1084/ jem. 20151978

67. Jiang C, Foley J, Clayton N, Kissling G, Jokinen M, Herbert R, et al. Abrogation of lupus nephritis in activation-induced deaminase-deficient MRL/lpr mice. J Immunol (2007) 178(11):7422-31. doi:10.4049/jimmunol.178.11.7422

68. Hsu HC, Yang P, Wu Q, Wang JH, Job G, Guentert T, et al. Inhibition of the catalytic function of activation-induced cytidine deaminase promotes apoptosis of germinal center B cells in BXD2 mice. Arthritis Rheum (2011) 63:2038-48. doi:10.1002/art.30257

69. Hase K, Takahashi D, Ebisawa M, Kawano S, Itoh K, Ohno H. Activationinduced cytidine deaminase deficiency causes organ-specific autoimmune disease. PLoS One (2008) 3(8):e3033. doi:10.1371/journal.pone.0003033

70. Jiang C, Zhao ML, Scearce RM, Diaz M. Activation-induced deaminasedeficient MRL/LPR mice secrete high levels of protective antibodies against lupus nephritis. Arthritis Rheum (2011) 63:1086-96. doi:10.1002/art.30230

71. Quartier P, Bustamante J, Sanal O, Plebani A, Debré M, Deville A, et al. Clinical, immunologic and genetic analysis of 29 patients with autosomal recessive hyper-IgM syndrome due to activation-induced cytidine deaminase deficiency. Clin Immunol (2004) 110:22-9. doi:10.1016/j.clim.2003.10.007

72. Bruhns P. Properties of mouse and human IgG receptors and their contribution to disease models. Blood (2012) 119:5640-9. doi:10.1182/ blood-2012-01-380121

73. Daëron M. Structural bases of Fc gamma R functions. Int Rev Immunol (1997) 16(1-2):1-27. doi:10.3109/08830189709045701

74. Pearse RN, Kawabe T, Bolland S, Guinamard R, Kurosaki T, Ravetch JV. SHIP recruitment attenuates Fc gamma RIIB-induced B cell apoptosis. Immunity (1999) 10(6):753-60. doi:10.1016/S1074-7613(00)80074-6

75. Xia Y, Pawar RD, Nakouzi AS, Herlitz L, Broder A, Liu K, et al. The constant region contributes to the antigenic specificity and renal pathogenicity of murine anti-DNA antibodies. J Autoimmun (2012) 39:398-411. doi:10.1016/j. jaut.2012.06.005

76. O'Keefe TL, Bandyopadhyay S, Datta SK, Imanishi-Kari T. V region sequences of an idiotypically connected family of pathogenic anti-DNA autoantibodies. J Immunol (1990) 144(11):4275-83.

77. Kabat ET, Wu M, Reid-Miller M, Reid-Miller M, Perry HM, Gottesman KS. Sequences of Proteins of Immunological Interest. Bethesda, MD: U S. Department of Health and Human Services. Public Health Service, National Institutes of Health (1987). 
78. Kearney JF, Radbruch A, Liesegang B, Rajewsky K. A new mouse myeloma cell line that has lost immunoglobulin expression but permits the construction of antibody-secreting hybrid cell lines. J Immunol (1979) 123(4):1548-50.

Conflict of Interest Statement: The authors declare that the research was conducted in the absence of any commercial or financial relationships that could be construed as a potential conflict of interest.
Copyright (c) 2017 McDonald, Medina, Pilichowska, Kearney, Shinkura, Selsing, Wortis, Honjo and Imanishi-Kari. This is an open-access article distributed under the terms of the Creative Commons Attribution License (CC BY). The use, distribution or reproduction in other forums is permitted, provided the original author(s) or licensor are credited and that the original publication in this journal is cited, in accordance with accepted academic practice. No use, distribution or reproduction is permitted which does not comply with these terms. 